University of Wollongong

Research Online

Faculty of Engineering and Information

Faculty of Engineering and Information

Sciences - Papers: Part A

Sciences

January 2013

\title{
An insight into the deformation and orientation development of severely plastic deformed aluminum
}

\author{
A K. Tieu \\ University of Wollongong, ktieu@uow.edu.au \\ G Y. Deng \\ University of Wollongong, gd577@uowmail.edu.au \\ C Lu \\ University of Wollongong, chenglu@uow.edu.au \\ L H. Su \\ University of Wollongong, lihongsu@uow.edu.au \\ H T. Zhu \\ University of Wollongong, hongtao@uow.edu.au
}

See next page for additional authors

Follow this and additional works at: https://ro.uow.edu.au/eispapers

Research Online is the open access institutional repository for the University of Wollongong. For further information contact the UOW Library: research-pubs@uow.edu.au 


\title{
An insight into the deformation and orientation development of severely plastic deformed aluminum
}

\begin{abstract}
Severe plastic deformation (SPD) techniques have attracted significant attention in the last two decades due to its capacity of producing bulk ultra-fine grained (UFG) or nanostructured materials, by imposing very high plastic strain. Equal channel angular pressing (ECAP), or equal channel angular extrusion (ECAE), is one of the most widely used SPD techniques. During ECAP, a sample is pressed through a die which consists of two channels with equal cross-section intersecting at an angle varying from 60 degrees to 150 degrees. Since the cross-section geometry of the sample remains nearly unchanged, the materials can be deformed to a very high strain by repeating the process. The deformation mechanism of ECAP is very complicated and it is dependent on the die geometry and material properties. It has been assumed as simple shear on the intersecting plane of two channels at ideal conditions, such as frictionless, perfectly plastic material and very sharp outer corner. However, from the view of texture evolutions, many experimental results have revealed the deviation from the ideal simple shear. Therefore, an insight into the deformation mechanism and orientation changes in the real ECAP case is still essential. In the present work, a comprehensive study based on the crystal plasticity finite element model (CPFEM) has been conducted to investigate the stress state, plastic strain, required load and crystallographic orientation development history of aluminum single crystals subjected to ECAP. The influence factors such as ECAP die geometry, frictional conditions and initial crystallographic orientations have been studied in detail. 2013 AIP Publishing LLC.
\end{abstract}

\section{Keywords}

deformed, insight, aluminum, deformation, orientation, into, development, severely, plastic

\section{Publication Details}

Tieu, A. K., Deng, G. Y., Lu, C., Su, L. H., Zhu, H. T., Liu, M. \& Liu, X. H. (2013). An insight into the deformation and orientation development of severely plastic deformed aluminum. AIP Conference Proceedings, 1532 (1), 206-213.

\section{Authors}

A K. Tieu, G Y. Deng, C Lu, L H. Su, H T. Zhu, M Liu, and X H. Liu 


\title{
An insight into the deformation and orientation development of severely plastic deformed aluminum
}

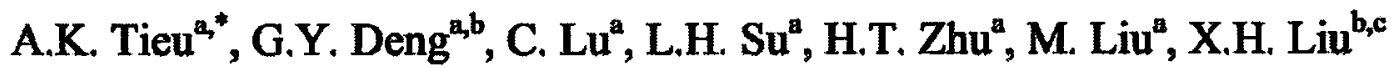 \\ "School of Mechanical, Materials and Mechatronic Engineering, University of Wollongong, Wollongong, NSW 2522, \\ Australia \\ ${ }^{b}$ State Key Lab of Rolling and Automation, Northeastern University, Shenyang, 110819, PR China \\ 'Northeastern University Research Academy, Northeastern University, Shemyang, 110819, PR China \\ "Email: kdieu@uow.ech.au
}

\begin{abstract}
Severe plastic deformation (SPD) techniques have attracted significant attention in the last two decades due to its capacity of producing bulk ultra-fine grained (UFG) or nanostructured materials, by imposing very high plastic strain. Equal channel angular pressing (ECAP), or equal channel angular extrusion (ECAE), is one of the most widely used SPD techniques. During ECAP, a sample is pressed through a die which consists of two channels with equal cross-section intersecting at an angle varying from $60^{\circ}$ to $150^{\circ}$. Since the cross-section geometry of the sample remains nearly unchanged, the materials can be deformed to a.very high strain by repeating the process. The deformation mechanism of ECAP is very complicated and it is dependent on the die genmetry and material properties. It has been assumed as simple shear on the intersecting plane of two chamels at ideal conditions, such as frictionless, perfectly plastic material and very sharp outer comer. However, from the view of texture evolutions, many experimental results have revealed the deviation from the ideal simple shear. Therefore, an insight into the deformation mechanisun and orientation changes in the real ECAP case is still essential. In the present work, a comprehensive study based on the crystal plasticity finite element model (CPFEM) has been conducted to investigate the stress state, plastic strain, required load and crystallographic orientation development history of aluminum single crystals subjected to ECAP. The influence factors such as ECAP die geometry, frictional conditions and initial crystallographic orientations have been studied in detail.
\end{abstract}

Keywords: Severe plastic deformation; Equal channel angular pressing; Equal channel angular extrusion; Crystal plasticity FEM.

\section{INTRODUCTION}

The fabrication of bulk materials with ultrafine grain sizes or nano grain sizes has attracted much attention in the last two decades because of the attractive properties including relatively high strength at ambient temperatures and a potential for utilization in superplastic forming operations at elevated temperatures [1]. Although several severe plastic deformation (SPD) techniques [2-4] are now available for the fabrication of UFG materials, the most promising and widely used procedure appears to be equal channel angular pressing (BCAP), which was developed by Segal et al. [2]. During ECAP, the workpiece is pressed through a die having two channels intersecting at an abrupt angle. In the theoretically ideal situation, including no friction, no strain hardening and very sharp outer comer, the sample is severely deformed by the simple shear acting along the intersection plane. The magnitude of effective plastic strain accumulated in the sample after ECAP can be estimated using an analytical expression proposed by Iwahashi et al. [5] as following:

$$
\bar{\varepsilon}=\frac{N}{\sqrt{3}}\left[2 \cot \left(\frac{\Phi+\Psi}{2}\right)+\Psi \operatorname{cosec}\left(\frac{\Phi+\Psi}{2}\right)\right]
$$

where $N$ is the number of ECAP passage, $\Phi$ is the die channel angle and $\Psi$ is the outer corner angle.

Up to now, there are numerous experimental reports in the literature describing the microstructure evolutions that develop through the application of ECAP. Mckenzie et al. [6] have studied the influence of back pressure on ECAP and it has been found that the back pressure leads to the increment of the resultant dislocation density in both the cell walls and the cell interiors. TEM analysis suggested two elongated laminar substructures forming along certain $\{111\}$ slip planes via a self-organized gliding of dislocations in copper [7]. According to [8], the inclination of grains with respect to the direction of ECAP was dependent on the distance from the top of the billet and changed from pass to pass. Su et al.[9] have processed aluminum at both room temperature and cryogenic temperature and the results

$$
\begin{gathered}
\text { The I1th Intermational Conference on Numerical Mathods in Industrial Forming Procasses } \\
\text { AlP Conf. Proc. 1532, 206-213 (2013), doi: 10.1063/1.4806826 } \\
22013 \text { AIP Publishing LC 978-0.7354-1156-2530.00 }
\end{gathered}
$$


revealed equiaxed microstructure after 8 ECAP passes at room temperature but elongated microstructure with smaller grain size at cryogenic temperature. Similar results can be found in [10] where the equilibrium grain size in pure $\mathrm{Al}$ is $\sim 1.2-1.3 \mu \mathrm{m}$ after pressing at room temperature. By contrast, the grain size is much smaller $(-0.27 \mu \mathrm{m})$ in the pure $\mathrm{Cu}$ after ECAP [11]. Besides, much effort has been contributed to understand the texture development after ECAP for both single crystals and polycrystalline materials [12-21], which is affected by many factors. The results in [19] indicated noticeable deviation from simple shear and heterogeneity across the billet thickness in each pass of BCAP deformation. However, most of those studies were only limited to one or two influence factors. Therefore, a systematic study with a powerful texture model is still needed.

In the present work, a comprehensive study of ECAP based on the developed crystal plasticity finite element model (CPFEM) [14-16] has been conducted, aiming to investigate the history of crystallographic orientation development and deformation heterogeneity during ECAP. Aluminum single crystals will be chosen to avoid the influence of the grain boundaries.

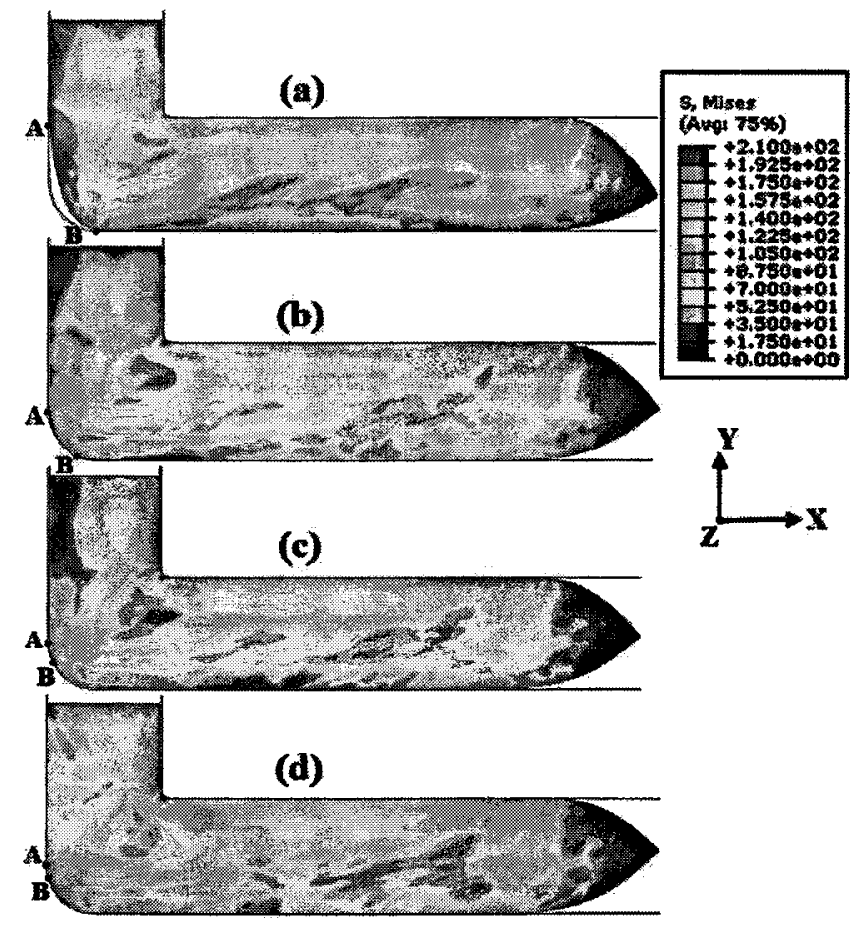

FIGURE 1. Influence of frictional conditions on the distribution of Mises stress in the deformed aluminum single crystals with initial crystallographic orientation A during ECAP. (a) $\mu=0$, (b) $\mu=0.05$, (c) $\mu=0.1$, and (d) $\mu=0.15$.

\section{SIMULATION DETAILS}

The crystal plasticity finite element model developed in [14-16] has been applied here. In addition, the ratedependent hardening model with a power law, which dictates the relationship of the resolved shear stress $\left(\tau^{(a)}\right)$ and the shear strain rate $\left(\gamma^{(\alpha)}\right)$ on a slip system $\alpha$, was used. Simulations were performed using the commercial software Abaqus/Standard ver.6.9.1. The constitutive laws were implemented into the finite element code by using the user material subroutine, which aimed to the calculation of crystallographic orientations, shear strength, shear strain and shear rate of each slip system considered during the deformation. The detailed procedures can be found in [22].

In order to save the computing time, two-dimensional simulations of the ECAP process were carried out by assuming the plane strain condition which has been proved to be reasonable in earlier experiments and simulations [23]. In the simulations, the dies and punches were modeled as rigid body and the punches moved at a constant speed of $2.4 \mathrm{~mm} / \mathrm{min}$ along the $-Y$ direction. Both the entry channel and exit channel have the same width of $4 \mathrm{~mm}$ as shown in FIGURE 1. In order to avoid distortion of the mesh due to the sharp inner comer, a small fillet radius was created on the die. Two different dies were designed. The first and second die has the channel angle of $90^{\circ}$ and 
and $150^{\circ}$ respectively, and these two dies have the same outer comer angle of $30^{\circ}$. The workpieces were assumed to be aluminum single crystals in order to avoid the influence of grain boundaries and the material parameters have been given in [14]. Two different initial crystallographic orientations (A and $B$ ) bave been studied in the present work. In orientation A, the slip plane $(-1-1-1)$ is parallel to the ideal shear plane and the slip direction $[-110]$ is parallel to the ideal shear direction. In orientation $B$, the normal of plane $(-4-12)$ is parallel to $Y$ and the normal of plane (1 23 ) is parallel to X. Coulomb friction model has been chosen to study the influence of frictional condition and four different coefficients of $\mu=0,0.05,0.1$ and 0.15 were used. One pass of ECAP at room temperature has been studied and the simulation details found in TABLE 1.

\section{RESULTS AND DISCUSSION}

\section{Influence of Frictional Condition}

In our previous study [12], it has been found that frictional condition significantly affect the texture evolution during ECAP, this section therefore will focus on the stress, plastic strain, required load and the deformation heterogeneity. FICURE 1 shows the distribution of Mises stress in the deformed crystals after ECAP. It is obvious that the stress is not uniform and the minimum value of Mises stress is located in the head part. Exiting from the plastic deformation zone (PDZ) leads to the maximum stress, which is located close to the inner comer of the die as shown in FIGURE 1(a). The magnitude of Mises stress remains nearly the same when $\mu$ rises from 0 to 0.15 . However, there is a significant influence on the stress distribution as shown in FIGURE 1, especially on the bottom part of the deformed samples. In addition, the increment of $\mu$ will benefit for the material filling in the die comer and leads to the decrement of the dead zone between the sample and die represented by the arc of " $A B^{\prime \prime}$ as marked in FIGURE 1.

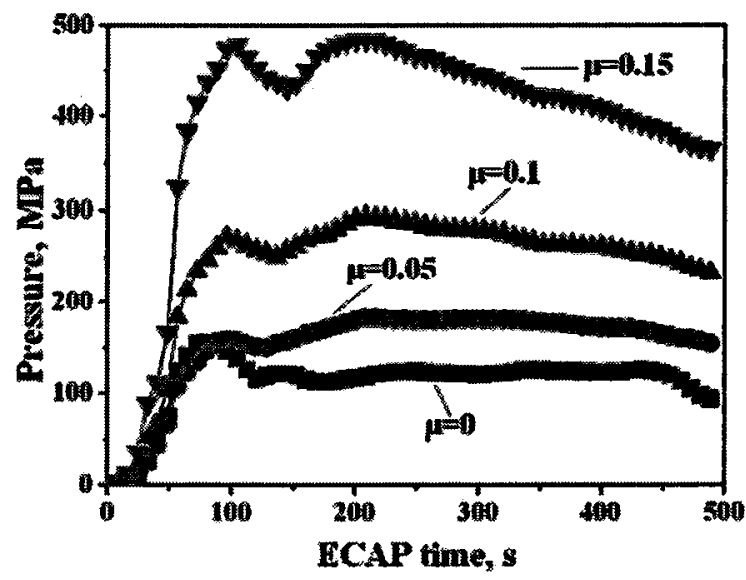

FIGURE 2. Influence of frictional conditions on the required load pressure in aluminum single crystals with initial crystallographic orientation A during ECAP as a function of the processing time.

In FIGURE 2, the required load pressure under all four different frictional conditions has been studied as a function of ECAP time. It is clear that three deformation steps can be distinguished under frictional conditions but only two steps exist in the frictionless condition. The larger frictional coefficient results in a higher load, and the peak pressure at the largest $\mu=0.15$ is three times more than that of $\mu=0$. Therefore, a suitable lubrication should be used when designing the ECAP process in order to reduce the cost.

A deformation inhomogeneity index, $C_{b}$ was defined to quantify the degree of deformation inhomogeneity along the thickness after ECAP by Li et al. [24] as following:

$$
C_{i}=\frac{\varepsilon_{\max }-\varepsilon_{\min }}{\varepsilon_{a v e}}
$$


where $\varepsilon_{\max }, \varepsilon_{\min }$ and $\varepsilon_{\text {avo }}$ indicate, resprectively, the maximum, minimum and average value of the effective plastic strains along the sample thickness.

For the ECAP die with $\Phi=90^{\circ}$ and $\Psi=30^{\circ}$, the effective plastic strain according equation (1) is about 1 . The deformation inhomogeneity index and average value of plastic strain have been calculated based on the simulation results for all four different frictional conditions in TABLE 1. As can be seen that, the effective plastic strain increases with the coefficient of friction (COF) $\mu$ and good agreement between simulation and theory [5] can be found when $\mu$ is less than 0.1. Moreover, $\mu=0.05$ leads to the minimum value of $C_{i}(\sim 1.381)$ and $\mu=0.15$ leads to the maximum value of $C_{i}(\sim 1.681)$.

TABLE (1). Influences of the frictional conditions, ECAP die channel angles and initial crystallographic orientation on the plastic strain and deformation heterogeneity in the deformed aluminum single crystals.

\begin{tabular}{|c|c|c|c|c|c|c|}
\hline Case number & Die angle & $\boldsymbol{\mu}$ & Orientation & $\bar{\varepsilon}$ & 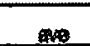 & $G_{1}$ \\
\hline 1 & $90^{\circ}$ & 0 & $\mathbf{A}$ & 1.016 & 1.159 & 1.428 \\
\hline 2 & $90^{\circ}$ & 0.05 & $\mathbf{A}$ & 1.016 & 1.161 & 1.381 \\
\hline 3 & $90^{\circ}$ & 0.1 & A & 1.016 & 1.195 & 1.406 \\
\hline 4 & $90^{\circ}$ & 0.15 & $\mathbf{A}$ & 1.016 & 1.353 & 1.681 \\
\hline 5 & $150^{\circ}$ & 0.05 & $\mathbf{A}$ & 0.302 & 0.274 & 1.539 \\
\hline 6 & $150^{\circ}$ & 0.05 & B & 0.302 & 0.291 & 1.725 \\
\hline
\end{tabular}

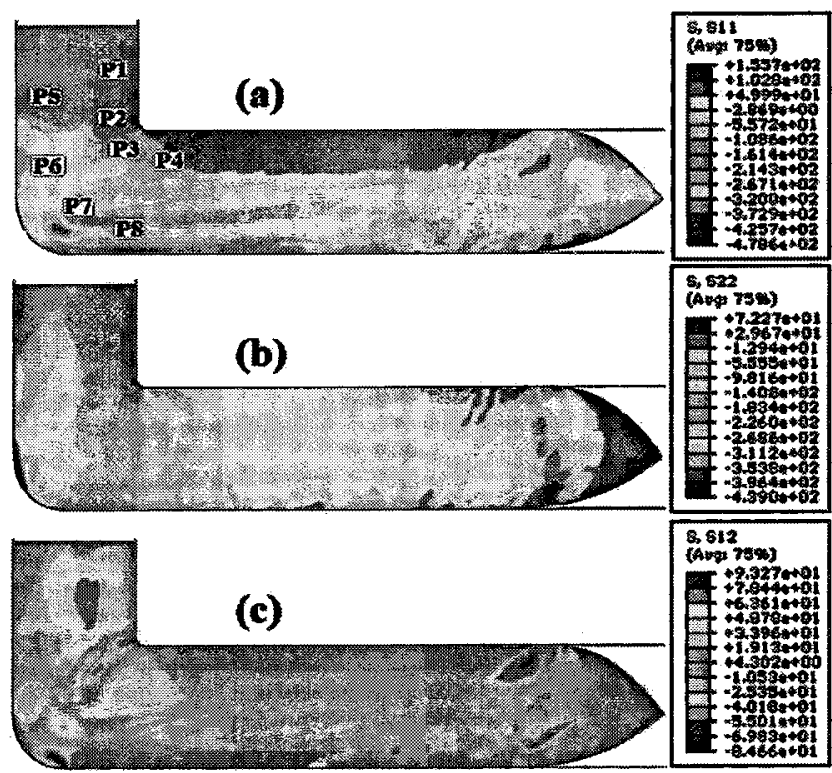

FIGURE 3. FEM predictions of the stress components $(a) S 11\left(\sigma_{x}\right),(b) S 22\left(\sigma_{y}\right)$, and (c) $S 12\left(\tau_{x y}\right)$ developed during ECAP for the $90^{\circ}$ ECAP die with $\mu=0.05$.

\section{Influence of Die Channel Angle}

The channel angle $\Phi$ is one of the key factors when designing the ECAP die and it has a significant influence on the microstructure and texture evolutions. In this section, two different ECAP dies (a $90^{\circ}$ die and a $150^{\circ}$ die) have been studied. Both dies have the same outer comer angle $\Psi$ of $30^{\circ}$.

FIGURE 3 shows the FEM predictions of the stresses developed during ECAP for the $90^{\circ}$ die with $\mu=0.05$. Stress components S11 $\left(\sigma_{x}\right)$, S22 $\left(\sigma_{y}\right)$, and S12 $\left(\tau_{x y}\right)$ denote the normal and shear stresses in the coordinate system $X Y Z$ as shown in FIGURE 1. It is obvious that the stresses are not uniform in the leading head and tail parts but relatively inhomogeneous in the steady state region. FGURE 3(a) indicates the large tensile stress of S11 in the upper part of the sample and compressive stress of S11 in the bottom part. In addition, the simulation shows large values of the compression stress S22 in FIGURE 3(b). FIGURE 3(c) reveals the inhomogeneous distribution of stress \$12 along the intersecting plane of two channels. The outer comer angle influence on the stress distribution 
can be obtained directly by comparing the present study with the simulation conducted by Semiatin et al. [25], where the outer comer angle is nearly zero.

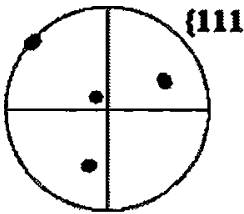

P1

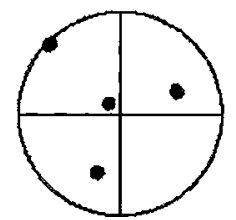

P5

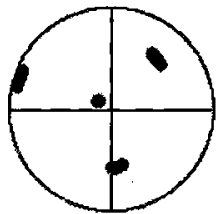

P2

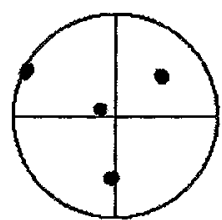

P6

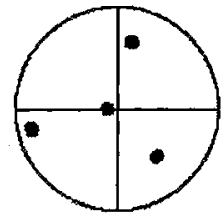

P3

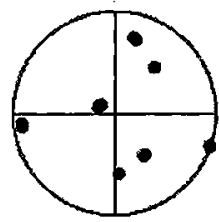

P7

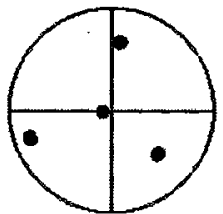

$\mathbf{P} 4$

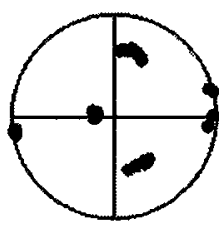

P8

FIGURE 4. The \{111\} pole figures of eight different selected positions marked in FGURE 3(a) during ECAP (90 die) of aluminum single crystal with initial crystallographic orientation $A$. $(\mu=0.05$ ) (sec Figure 3 (a) for notation PI to P8).

In order to study the texture evolution history during the $90^{\circ}$ die, eight different positions (P1-P8) have been selected as marked in FIGURE 3. The corresponding $\{111\}$ pole figures have been plotted in FIGURE 4. As can be seen, the crystallographic orientation rotates progressive from initial component when the material passes through the intersecting zone of the entry channel and exit channel.

FIGURE S(a) shows the FEM predictions of the stresses developed in the aluminum single crystal with initial crystallographic orientation A during ECAP for the $150^{\circ}$ die with $\mu=0.05$. The results reveal a significant influence of the channel angle, and the $150^{\circ}$ channel angle produces much smaller stress than that of $90^{\circ}$. The stresses shown in FIGURE 5 indicate more bending than shear at the larger die channel angle. Comer gaps in both the outer comer and exit channel have been developed. The theoretical plastic strain according to Eq. (1) is about 0.302 for the $150^{\circ}$ die with a $30^{\circ}$ outer comer angle. But the average effective plastic strain based on the simulation is about 0.274 , and much smaller than the theoretical value as shown in TABLE 1. In addition, the larger channel angle leads to the larger deformation inhomogeneity index $C_{i}$ for aluminum single crystal with initial orientation $A$ even at the same frictional condition, which is 1.381 in the $90^{\circ}$ die and 1.539 in the $150^{\circ}$ die, respectively. 

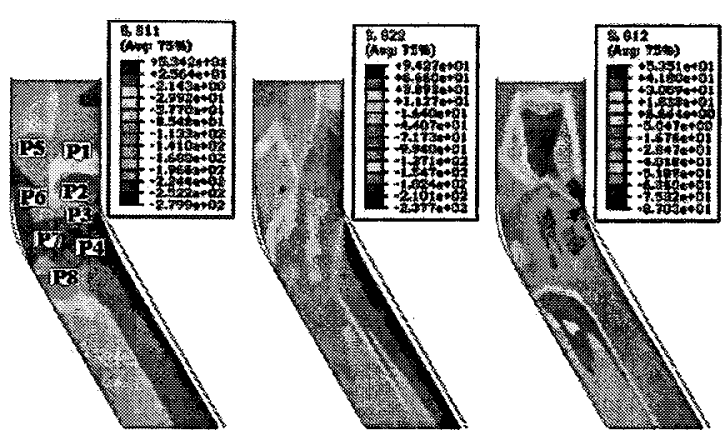

(a) Orientation-A
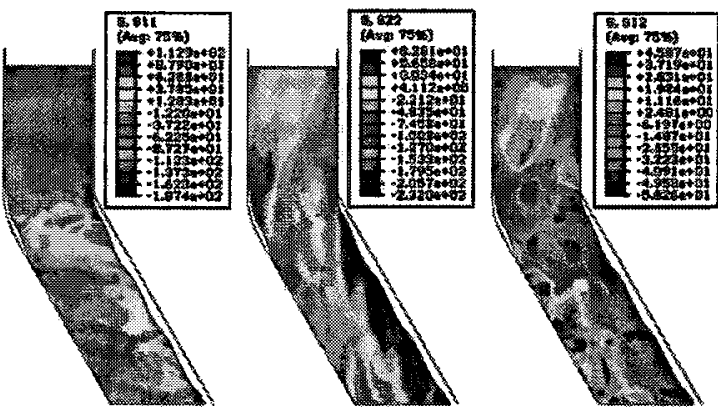

(b) Orientation-B

FIGURE 5. FEM predictions of the stress components S11 $\left(\sigma_{x}\right), S 22\left(\sigma_{y}\right)$, and S12 $\left(\tau_{x y}\right)$ developed during ECAP for the $150^{\circ}$ ECAP die with $\mu=0.05$. Aluminum single crystals were initially oriented with (a) crystallographic orientation $A$, and (b) crystallographic orientation $B$.

The required loads for ECAP between these two different die channel angles have been compared in FIGURE 6. It is clearly seen that three similar deformation steps can be distinguished for the same initial crystallographic orientation A. Not surprisingly, the peak pressure for the $150^{\circ}$ die is only $1 / 4$ of that for the $90^{\circ}$ die, where the corresponding maximum force is approximately $2494 \mathrm{~N}$.

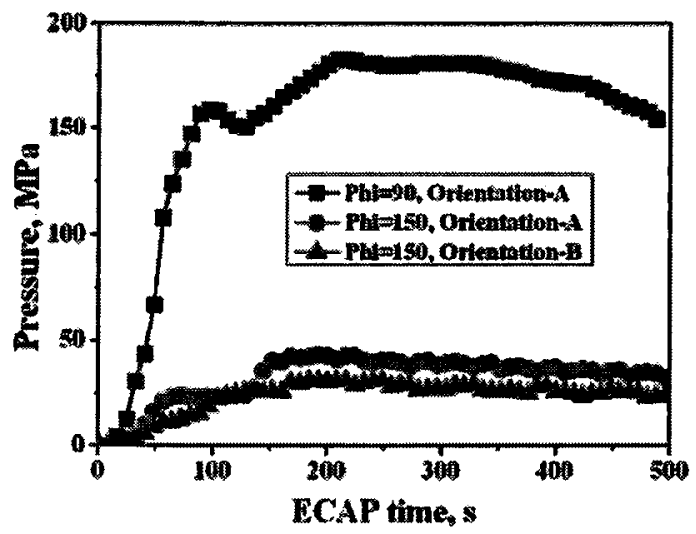

FIGURE 6. Influence of die channel angle and initial crystallographic orientation on the required load pressure of aluminum single crystals during ECAP as a function of the processing time.

Similar to the $90^{\circ}$ ECAP die, eight different positions as marked in FIGURE S(a) have been selected to study the crystallographic orientation development in the $150^{\circ}$ die. The $\{111\}$ pole figures at positions PI and P5 reveal the initial crystallographic orientation A before the material enters the PDZ. Then the crystal starts rotating mainly around the transverse direction in a counter-clock wise sense as shown at positions (P2, P3, P6 and P7) in the 
FIGURE 7 when the material passes through the PDZ. The pole figure at position P8 indicates a slightly larger crystal rotation than at position P4, due to the presence of the outer comer and comer gap developed between the sample and ECAP die.

\section{Influence of Initial Orientation}

It is known that the single crystal offers two significant advantages in fundamental investigations during ECAP [13]. First, it is possible to design the initial crystallographic orientation. Second, direct evaluation can be obtained by avoiding the influence of grain boundary. Two different initial orientations will be studied in this section during ECAP with $150^{\circ}$ die.

FICURE 5 shows the comparison of the stresses between two orientations A and B. It can be seen that the orientation B leads to much more inhomogeneous distribution of the stresses in the sample and a larger comer gap in the outer corner developed. Besides, both of the stress components S22 and S12 in orientation B are slightly smaller than in the orientation A. According to NGURE 6, the required load is larger in orientation A by comparing with orientation B, where the pressure increases slowly with the deformation time and then reaches to the steady deformation state.

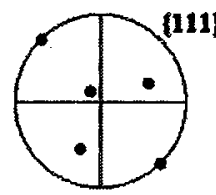

P1

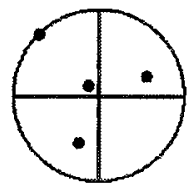

P5

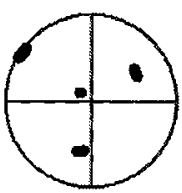

I2

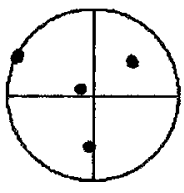

P6

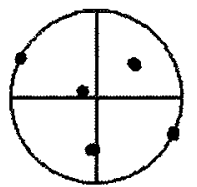

P3

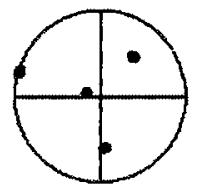

P7

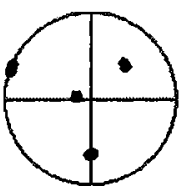

P4

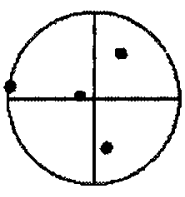

P8

FIGURE 7. The \{111\} pole figures of eight different selected positions marked in FIGURE S(a) during ECAP (150 die) of aluminum single crystal with initial crystallographic orientation $A .(\mu=0.05)$

The simulated effective plastic strain has been compared with the theoretical value according to equation (1) as shown in TABLE 1 and good agreement bas been observed. The theoretical plastic strain is about 0.302 and the simulated strain is 0.291 , which is 0.274 for orientation $B$. In addition, a larger deformation inhomogeneity in orientation $B$ was observed in term of $C_{i}(-1.725)$. The $\{111\}$ pole figures for orientation $B$ in FIGURE 8 revealed the slight larger crystallographic rotation angle at positions close to the outer comer than the inner comer.

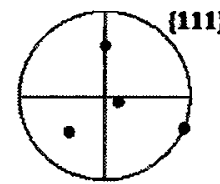

P1

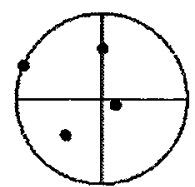

P5

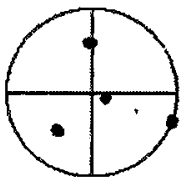

P2

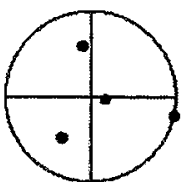

P6

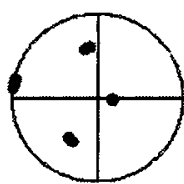

P3

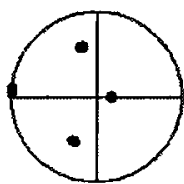

77

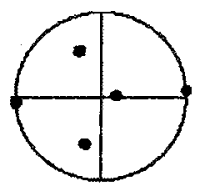

P4

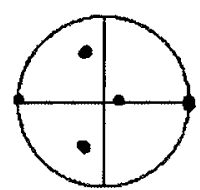

P8

FICURE 8. The $\{111\}$ pole figures of eight different selected positions during ECAP $\left(150^{\circ}\right.$ die) of aluminum single crystal with initial crystallographic orientation B. $(\mu=0.05)$ 


\section{CONCLUSIONS}

In the present study, a crystal plasticity finite element model has been successfully used to conduct a systematical investigation of aluminum single crystals during ECAP at room temperature. The simulation results revealed significant influence of frictional condition between sample and the die on the stress, plastic strain, required load and deformation behaviors. The larger friction coefficient leads to the obvious increment of peak load and it has been observed that the peak load at $\mu=0.15$ is three times more than at frictionless condition. The influences of channel angle and initial crystallographic orientation on the stress state, required load and history of orientation development have also been carefully examined. The crystal rotation angle at $150^{\circ}$ die is much smaller than at $90^{\circ}$ die, where a larger plastic strain can be observed.

\section{ACKNOWLEDGMENTS}

Simulations were performed using the HPC cluster of University of Wollongong and the computing facilities provided by NCI National Facility of Australia.

\section{REFERENCES}

1. R. Z. Valiev and T. G. Langdon, Prog. Mater. Sei. 51, 881-981 (2006).

2. V. M. Segal, V. I. Rereznikov, A. E. Drobyshebskiy, V. I. Kopylov, Russ. Metall. 1, 99-105 (1981).

3. L. H. Su, C. Lu, A. K. Tieu, G. Y. Deng, X. D. Sun, Mater. Sci. Eng. A 559, 345-351 (2013).

4. Z. Wang, U. Garbe, H. Li, A. J. Studer, R. P. Harrison, M. D. Callaghan, Y. Wang, X. Liao, Scripta Mater. 67, 752-755 (2012).

5. Y. Iwahashi, J. Wang, Z. Horita, M, Nemoto, T. G. Langdon, Scripta Mater. 35, 143-146 (1996).

6. P. W. J. Mckenvie, R. Lapovok, Y. Estrin, Acta Mater. 55, 2985-2993 (2007).

7. Q. Xue, I. J. Beyerlein, D. J. Alexander, G. T. Gray III, Acta Mater. 55, 655-668 (2007).

8. W. Skrotaki, N. Scheerbaum, C. G. Oertel, H. G. Brokmeicr, S. Suwas, L. S. Toth, Acta Mater. 55, 2211-2218 (2007).

9. L. H. Su, C. Lu, L. Z. He, L. C. Zhang, P. Guagliardo, A. K. Tieu, S. N. Samarin, J. F. Williams, H. J. Li, Acta Mater. 60 , 4218-4228 (2012).

10 S. D. Terhune, D. L. Wisher, K. Oh-ishi, Z. Horita, T. G. Langdon, Metall. Mater. Trans. A 33, 2173-2179 (2002).

11. S. Komurs, Z. Horite, M. Nemoto, T. G. Langdon, J. Mater. Res. 14, 4044-4051 (1999).

12. G. Y. Deng, C. Lu, A. K. Tieu, L. H. Su, N. N. Huynh, X. H. Liu, J. Mater. Sci. 45, $4711-4717$ (2010).

13. Y. Fukuda, K. Oh-ishi, M. Furukawa, Z. Horita, T. G. Langdon, Acta Mater, 52, 1387-1395 (2004).

14. C. Lu, G. Y. Deng, A. K. Tieu, L. H. Su, H. T. Zhu, X. H. Liu, Acta Mater. 59, 3581-3592 (2011).

15. G. Y. Deng, C. Lu, L. H. Su, A. K. Tiew, X. H. Liu, J. Comp. Theo. Nanasci. 9, 1481-1484 (2012).

16. G. Y. Deng, C. Lu, L. H. Su, X. H. Liu, A. K. Tieu, Mater. Sel. Eng. A 534, 68-74 (2012).

17. W. Z. Han, Z. F. Zhang, S. D. Wu, S. X. Li, Acta. Mater, 55, 5889-5900 (2007).

18. M. Furukawa, Y. Kawasaki, Y. Mìyahara, Z. Horita, T. G. Langdon, Mater. Sci. Eng. A 410-411, 194-200 (2005).

19. S. Li, A. A. Gazder, L. J. Beyerlein, E. V. Pereloma, C. H. J. Davies, Acta Mater. 54, 1087-1 100 (2006).

20. A. A. Gazder, S. Li, F. H. Dalla Torre, I. J. Beyerlein, C. F. Gu, C. H. J. Davies, E. V. Pereloma, Mater. Sei. Eng, A 437, 259267 (2006).

21. I. J. Beyerlein, L. S. Toth, Prog. Mater. Sci. 54, 427-510 (2009).

22. L. Y. Si, C. Lu, N. N. Huynh, A. K. Tieu, X. H. Lin, J. Mater. Process Tech. 201, 79-84 (2008).

23. A. Gholinia, P. Bate, P. B. Prangnell, Acta Mater. 50, 2121-2136 (2002).

24. S. Li, M. A. M. Bourke, I. J. Beyerlein, D. J. Alexander, B. Clausen, Mater. Sci. Eng. A 51, 881-981 (2006).

25. S. L. Serniatin, D. P. Delo and E. B. Shell, Acta Mater. 48, 1841-1851 (2000). 